\title{
Acute effect of dietary stanyl ester dose on post-absorptive $\alpha$-tocopherol, $\beta$-carotene, retinol and retinyl palmitate concentrations
}

\author{
Heikki Relas, Helena Gylling, and Tatu A. Miettinen* \\ Division of Internal Medicine, Department of Medicine, University of Helsinki, PO Box 340, FIN-00029 HYKS, Helsinki, \\ Finland
}

(Received 10 December 1999 - Revised 16 June 2000 - Accepted 1 August 2000)

\begin{abstract}
Stanyl esters dissolved in margarine inhibit cholesterol absorption, lower sterol absorption in general, and lower serum total cholesterol, LDL-cholesterol and plant sterol levels. To find out whether stanyl esters inhibit absorption of fat-soluble vitamins and $\beta$-carotene in acute experiments, we performed two fat-tolerance tests fortified with vitamins (retinol 0.9 $3.7 \mathrm{mg}, \alpha$-tocopherol $70-581 \mathrm{mg}), \beta$-carotene $(25-150 \mathrm{mg})$ and squalene $(0.5 \mathrm{~g})$ with and without $1 \mathrm{~g}$ of stanyl ester added to the test meal in ten healthy men. The concentrations or areas under the curves (AUC) of cholesterol, triacylglycerols, squalene and $\alpha$-tocopherol, $\beta$-carotene and retinyl palmitate showed typical postprandial changes in serum, chylomicrons, VLDL and VLDL infranatant (intermediate-density lipoproteins, LDL and HDL) over $24 \mathrm{~h}$ after the test meal without stanyl esters, and they were not affected by the addition of stanyl esters. The postabsorptive serum campesterol concentration and campesterol:cholesterol were significantly lowered at 6-9 h by stanyl ester supplementation, reflecting reduced sterol absorption efficiency. Changes in vitamin and $\beta$-carotene AUC did not correlate with the given doses. In conclusion, the present study shows that stanyl esters dissolved in margarine do not detectably interfere in a short-term study with the absorption of $\alpha$-tocopherol, $\beta$-carotene or retinol measured by a $24 \mathrm{~h}$ oral fat-load test.
\end{abstract}

Stanyl esters: Fat-soluble vitamins: $\beta$-Carotene: Squalene

Dietary plant sterols have been shown to reduce serum cholesterol levels in human subjects since the 1950s (Pollak, 1953). Sitostanol, a $5 \alpha$-saturated sitosterol derivative, reduces the intestinal absorption of cholesterol more effectively than sitosterol, and is less well absorbed from the intestine (Sugano et al. 1977; Ikeda \& Sugano, 1978; Heinemann et al. 1986, 1991; Ikeda et al. 1989; Becker et al. 1993). Sitostanyl ester, a fat-soluble form of sitostanol, has been shown to reduce serum total cholesterol and LDL-cholesterol levels, and serum plant sterols (campesterol and sitosterol) when added to a daily meal (Miettinen et al. 1995).

The exact cholesterol-lowering mechanism of stanyl esters, however, is not yet known. It has been shown in rats that the concentration of sitostanol-containing micelles in the jejunum is the important factor in suppression of cholesterol absorption (Hassan \& Rampone, 1980; Ikeda et al. 1989). Sitostanol reduces the concentration of cholesterol in micelles both in vitro and in vivo, and reduces the micellar solubility of cholesterol in vivo (Ikeda et al. 1989). Plant sterols have been shown to interfere with cholesterol absorption more effectively when administered simultaneously with cholesterol (Mattson et al. 1982). As the absorption of $\alpha$-tocopherol (Hollander et al. 1975), $\beta$ carotene (Hollander \& Ruble, 1978) and retinol (Hollander, 1981) are passive diffusion processes taking place with the intestinal lipids, their absorption is facilitated by simultaneous ingestion of fat. Accordingly, dietary stanyl esters might interfere with the absorption of fat-soluble vitamins. In fact, it has been shown previously in a long-term study (Gylling et al. 1999a) that sitostanyl ester reduced the serum level of $\beta$-carotene, even in relation to cholesterol, but not that of retinol, which is a more polar compound than $\beta$-carotene.

Dietary retinyl esters are hydrolysed to retinol in the intestinal lumen and thereafter absorbed into the enterocyte (Goodman et al. 1965) where they are re-esterified and transported in chylomicrons and chylomicron remnants to the liver (Kanai et al. 1968). It is estimated that up to $75 \%$ of the dietary retinol is absorbed in the small intestine

\footnotetext{
Abbreviation: AUC, area under the curve.

* Corresponding author: Professor Tatu Miettinen, fax +358947174013, email tatu.a.miettinen@helsinki.fi
} 
(Biesalski, 1997). $\beta$-Carotene, a precursor of vitamin A, has a completely different method of absorption. Approximately $9-17 \%$ of the dietary $\beta$-carotene, is absorbed via the lymphatic system (Goodman et al. 1966). In the enterocyte $\beta$-carotene is partly degraded to two retinaldehyde molecules and eventually into retinol (Goodman \& Olson, 1969). Thus $60-70 \%$ of the absorbed $\beta$-carotene is recovered as retinyl esters and about $15 \%$ remains as intact $\beta$-carotene (Goodman et al. 1966). Postprandial maximal serum $\beta$-carotene concentration has been documented as much as $36 \mathrm{~h}$ after administration (Cornwell et al. 1962). Orally-administered $\alpha$-tocopherol is absorbed in chylomicrons (Traber et al. 1990) and, similarly to other lipidsoluble compounds, requires bile acids for micellar formation (Gallo-Torres, 1970). Peak postprandial concentrations are detected 6-12 $\mathrm{h}$ after administration (Traber et al. 1988, 1990). About $45 \%$ of an oral dose is absorbed into the lymph (Meydani, 1995).

The aim of the present study was to investigate the effect of a single stanyl ester dose in a test meal containing variable amounts of vitamins and squalene on postprandial cholesterol metabolism and absorption of $\alpha$-tocopherol, $\beta$ carotene and retinol in healthy volunteers.

\section{Experimental methods}

\section{Subjects}

The study group consisted of ten healthy men with a mean age of 52 (SE 5) years. The subjects had no known history of renal, liver, thyroid or gastrointestinal diseases, or any hypolipidaemic medication. The study protocol was accepted by the Ethics Committee of our hospital.

\section{Study design}

The subjects visited the outpatient clinics twice, 2 weeks apart. A fat-load test was performed during both visits. The test was started at 08.00 hours after a $12 \mathrm{~h}$ fast. After the baseline blood samples were withdrawn from the forearm vein into light-protected $10 \mathrm{ml}$ tubes (Venoject Autosep ${ }^{\circledR}$; Terumo Europe, Leuven, Belgium), the subjects were given a fatty meal containing $90 \mathrm{~g}$ fat, $432 \mathrm{mg}$ cholesterol and $0.5 \mathrm{~g}$ squalene. The test meals were supplemented with a mixture of vitamins (retinol $0.9-3.7 \mathrm{mg}$ and $\alpha$-tocopherol $70-581 \mathrm{mg}$ ) and $\beta$-carotene $25-150 \mathrm{mg}$ (Table 1). The fatsoluble vitamins and $\beta$-carotene have markedly variable absorption percentages. To observe possible effects of dosage, two to three different dosages were used for vitamins and $\beta$-carotene. Margarine $(8 \mathrm{~g})$ with or without 1 g stanyl ester (Raisio Group, Raisio, Finland) was added to the fat load in random order. The stanyl ester mixture

Table 1. Doses of vitamins and $\beta$-carotene $(\mathrm{mg})$ given to each of the ten male subjects with their test meals

\begin{tabular}{lcccc}
\hline Subject no. ... & 1 and 2 & 3 and 4 & $5-7$ & $8-10$ \\
\hline$\alpha$-Tocopherol & 71 & 281 & 281 & 581 \\
Retinol & 0.9 & 3.7 & 3.7 & 3.7 \\
$\beta$-Carotene & 25 & 100 & 150 & 150 \\
\hline
\end{tabular}

was mainly composed of sitostanyl ester (92\%). The contents of the major fatty acids in the margarine were $(\mathrm{g} /$ $100 \mathrm{~g}): 16: 0$ 16.7, $18: 147 \cdot 3,18: 217 \cdot 7,18: 38 \cdot 9$. The total amount of trans-fatty acids was 0.5 . The margarine did not have a vitamin supplement. The test meal was given as a cream-egg shake. After the test meal, the subjects fasted for $9 \mathrm{~h}$ before having their first normal meal of standard low-fat low-cholesterol hospital food. Postprandial blood samples were withdrawn after 3, 4, 6, 9, 12 and $24 \mathrm{~h}$. The samples were stored at $-20^{\circ} \mathrm{C}$ until analysed.

\section{Analytical methods}

Commercial kits were used to analyse enzymically serum total cholesterol and triacylglycerol and lipoprotein-cholesterol and -triacylglycerols (Roche Diagnostics; Hoffman-La Roche Ltd, Basel, Switzerland). Lipoproteins from fasting serum samples were separated by ultracentrifugation in a fixed-angle type $50.4 \mathrm{Ti}$ rotor (Beckman Instruments Inc., Fullerton, CA, USA) into the following densities (g/ml; Warnick \& Alberts, 1982): VLDL < 1.006, intermediate-density lipoproteins 1.006-1.019, LDL 1.019-1.063, HDL 1.063-1.21. Chylomicrons and VLDL were separated from postprandial samples as follows: $7.2 \mathrm{ml}$ serum was overlayered with an $\mathrm{NaCl}$ solution of density $1.0063 \mathrm{~g} / \mathrm{ml}$ and centrifuged at $34873 \boldsymbol{g}$ (18 $000 \mathrm{rpm}$ ) for $30 \mathrm{~min}$. Chylomicrons were isolated by aspirating the top $3.6 \mathrm{ml}$. To separate VLDL, the infranatant was mixed with an $\mathrm{NaCl}$ solution of density $1.0063 \mathrm{~g} / \mathrm{ml}$ and centrifuged at $131849 \mathrm{~g}(35000 \mathrm{rpm})$ for $18 \mathrm{~h}$. VLDL was aspirated as the top $3.6 \mathrm{ml}$. The bottom fraction contained the remaining intermediate-density lipoproteins, LDL and HDL (VLDL infranatant).

Serum squalene and non-cholesterol sterols as nonsaponifiable lipids were quantified using GLC with a $50 \mathrm{~m}$ HP Ultra 1 SE-30 capillary column (Hewlett-Packard Co., Wilmington, DE, USA; Miettinen \& Koivisto, 1983; Miettinen, 1988). Squalene is a cholesterol precursor, which reflects postprandial chylomicron remnant transport (Gylling \& Miettinen, 1994). Serum cholesterol-precursor sterol levels reflect cholesterol synthesis, and those of serum plant sterols (campesterol and sitosterol) reflect the absorption efficiency of cholesterol (Tilvis \& Miettinen, 1986). The analyses of $\alpha$-tocopherol, $\beta$-carotene, retinol and retinyl palmitate were carried out using reverse-phase HPLC (Schäfer Elinder \& Walldius, 1992) on a $20 \mathrm{~cm}$ ODS Hypersil column (Hewlett-Packard Co.) using $\alpha$ tocopheryl acetate as internal standard. The HPLC system comprised a 2150 HPLC Pump, 2152 LC Controller, 2157 Autosampler (Pharmacia LKB, Uppsala, Sweden), and a HP 1050 Diode Array Detector (Hewlett-Packard Co.). Serum or lipoprotein samples $(0.4 \mathrm{ml})$ were extracted into heptane, dried under $\mathrm{N}_{2}$ and reconstituted in $0.1 \mathrm{ml}$ mobile phase, which consisted of acetonitrile-water-tetrahydrofuran $(81 \cdot 3: 5 \cdot 7: 13$, by vol.); the flow rate was $0 \cdot 4 \mathrm{ml} / \mathrm{min}$. The column temperature was maintained at $40^{\circ} \mathrm{C}$. Injected samples $(5 \mu \mathrm{l})$ were separated in the mobile phase on a $20 \mathrm{~cm}$ ODS Hypersil column (Hewlett-Packard Co.). The detection wavelengths $(\mathrm{nm})$ were: $\alpha$-tocopheryl acetate 285, $\alpha$-tocopherol 292, retinol and retinol palmitate 326 , $\beta$ carotene 450. All samples obtained from an individual 
subject were analysed on the same day. The between-day CV varied between 9.2 and $11.9 \%$, and the within-day CV varied between 2.2 and $8.0 \%$.

\section{Calculations}

Postprandial triacylglycerol, retinyl palmitate and squalene are expressed as concentrations or are given as incremental values calculated by subtracting the respective fasting value from each postprandial value. Postprandial responses were also quantified by calculating the area under the curve (AUC) and the incremental area between the zero level and the $24 \mathrm{~h}$ concentration curve for each subject. For triacylglycerols and cholesterol, incremental areas under curves were calculated from their respective $9 \mathrm{~h}$ concentration curves, since after $9 \mathrm{~h}$ some of the values were negative. As the baseline concentrations of the compounds studied were similar for both fat loads, and due to frequent negative incremental values, we preferred to use AUC rather than incremental area under the curve in the following.

\section{Statistical analysis}

The data are expressed as means with their standard errors. The level of statistical significance was taken as $P<0 \cdot 05$. ANOVA for repeated measures was used to test the stanyl ester effects and time $\times$ stanyl ester interaction for postprandial triacylglycerol, cholesterol, squalene and campesterol: cholesterol concentration curves. Follow-up comparisons were made by one-way ANOVA at each time point. In addition, Student's two-sided $t$ test and paired $t$ test were used when appropriate. Due to the different doses of vitamins used, non-parametric statistics (Fisher's exact probability test and the Wilcoxon signed-rank test) were used to test the differences of vitamin responses. Logarithmic transformations were used for skewed distributions.

\section{Results}

Fasting serum total and lipoprotein lipid values and serum vitamin and $\beta$-carotene levels are shown in Table 2. $\alpha$ Tocopherol and $\beta$-carotene were carried mainly in the VLDL infranatant, and there were no differences between the fasting and postprandial states, whereas $45-55 \%$ of the retinyl palmitate and squalene were carried in chylomicrons and VLDL $9 \mathrm{~h}$ after the test meal (Table 3). The recovery of retinol in the VLDL infranatant was $100 \%$ both in the fasting state and postprandially (data not shown).

Stanyl ester supplementation had no effect on postprandial serum total, chylomicron (Fig. 1) or VLDLtriacylglycerol, -cholesterol and -squalene concentrations or their respective AUC.

In the following analyses, non-parametric tests were used due to the different doses of vitamins and $\beta$-carotene administered. Serum $\beta$-carotene AUC decreased in five subjects and increased in five subjects ( $P$ 0.34), $\alpha$ tocopherol AUC decreased in six and increased in four subjects $(P \quad 0.24)$ and retinyl palmitate AUC increased in six, decreased in two and remained unchanged in two subjects ( $P$ 0.06; Fig. 2). The percentage changes in AUC
Table 2. Baseline characteristics of healthy male volunteers participating in the study*

(Mean values with their standard errors and ranges for ten men)

\begin{tabular}{|c|c|c|c|}
\hline Characteristics & Mean & SE & Range \\
\hline Age (years) & $52 \cdot 3$ & $5 \cdot 3$ & $26-67$ \\
\hline BMI $\left(\mathrm{kg} / \mathrm{m}^{2}\right)$ & $23 \cdot 8$ & 1.4 & $16 \cdot 6-33 \cdot 6$ \\
\hline \multicolumn{4}{|l|}{ Cholesterol (mmol/l): } \\
\hline Total serum & $5 \cdot 0$ & 0.3 & $3 \cdot 8-6 \cdot 2$ \\
\hline VLDL & 0.50 & 0.12 & $0.13-1.40$ \\
\hline IDL & 0.14 & 0.02 & $0.07-0.24$ \\
\hline LDL & 2.45 & 0.22 & $1 \cdot 80-4.00$ \\
\hline $\mathrm{HDL}$ & $1 \cdot 28$ & $0 \cdot 10$ & $0.85-1.83$ \\
\hline \multicolumn{4}{|l|}{ Triacylglycerol (mmol/l): } \\
\hline Total serum & 1.43 & 0.28 & $0.64-3.49$ \\
\hline VLDL & 0.98 & 0.26 & $0.28-2 \cdot 81$ \\
\hline IDL & 0.07 & 0.01 & $0.04-0.11$ \\
\hline LDL & $0 \cdot 18$ & 0.02 & $0.13-0.30$ \\
\hline HDL & 0.14 & 0.02 & $0.10-0.25$ \\
\hline Serum: $\alpha$-Tocopherol $(\mu \mathrm{mol} / \mathrm{l})$ & $34 \cdot 8$ & $3 \cdot 0$ & $21 \cdot 9-49 \cdot 4$ \\
\hline$\beta$-Carotene $(\mu \mathrm{mol} / \mathrm{l})$ & 1.00 & 0.24 & $0.26-2.91$ \\
\hline Retinol $(\mu \mathrm{mol} / \mathrm{l})$ & 3.46 & 0.38 & $1 \cdot 74-5 \cdot 35$ \\
\hline Campesterol ( $\mu \mathrm{g} / \mathrm{l})$ & 4206 & 516 & $2477-7112$ \\
\hline Sitosterol $(\mu \mathrm{g} / \mathrm{l})$ & 2239 & 262 & $1239-3917$ \\
\hline
\end{tabular}

IDL, intermediate-density lipoprotein.

* For details of procedures, see p. 142.

were not significant: $\beta$-carotene -2.94 (SE 11.8); $\alpha$ tocopherol +1.8 (SE 11.3); retinyl palmitate +16.9 (SE $9 \cdot 0$ ). The different doses of vitamins and $\beta$-carotene did not correlate with the changes in AUC due to supplementation with stanyl esters (data not shown). Fig. 2 shows that the presence of stanyl ester in the test meal had no consistent effect on the AUC for $\beta$-carotene, $\alpha$-tocopherol or retinyl palmitate. Stanyl esters had no effect on peak postprandial serum concentration times of the compounds studied (Table 4).

Table 3. Distribution (\%) of $\alpha$-tocopherol, $\beta$-carotene, retinyl palmitate and squalene in chylomicrons, VLDL and VLDL infranatant in the fasting state and $9 \mathrm{~h}$ after the test meal in healthy male volunteers*

(Mean values with their standard errors for ten men)

\begin{tabular}{|c|c|c|c|c|}
\hline & \multicolumn{2}{|c|}{ Fasting } & \multicolumn{2}{|c|}{ Postprandial } \\
\hline & Mean & SE & Mean & SE \\
\hline \multicolumn{5}{|l|}{$\alpha$-Tocopherol } \\
\hline Chylomicron & $5 \cdot 4$ & $1 \cdot 3$ & $6 \cdot 0$ & 1.0 \\
\hline VLDL & $11 \cdot 6$ & $3 \cdot 8$ & $10 \cdot 7$ & $5 \cdot 2$ \\
\hline VLDL infranatant $†$ & 83.0 & $4 \cdot 4$ & $83 \cdot 3$ & $5 \cdot 8$ \\
\hline \multicolumn{5}{|l|}{$\beta$-Carotene } \\
\hline Chylomicron & 0.0 & 0.0 & $0 \cdot 0$ & 0.0 \\
\hline VLDL & $2 \cdot 0$ & $1 \cdot 1$ & $4 \cdot 7$ & $3 \cdot 2$ \\
\hline VLDL infranatant & $98 \cdot 0$ & $1 \cdot 1$ & $95 \cdot 3$ & $3 \cdot 2$ \\
\hline \multicolumn{5}{|l|}{ Retinyl palmitate } \\
\hline Chylomicron & 0.0 & $0 \cdot 0$ & $18 \cdot 9$ & $6 \cdot 0$ \\
\hline VLDL & $32 \cdot 5$ & 14.5 & $27 \cdot 0$ & $7 \cdot 5$ \\
\hline VLDL infranatant & $67 \cdot 5$ & 14.5 & $54 \cdot 1$ & $11 \cdot 1$ \\
\hline \multicolumn{5}{|l|}{ Squalene } \\
\hline Chylomicron & $7 \cdot 7$ & $1 \cdot 2$ & $24 \cdot 3$ & $2 \cdot 3$ \\
\hline VLDL & $27 \cdot 0$ & 2.7 & 33.4 & 2.9 \\
\hline VLDL infranatant† & $65 \cdot 3$ & 2.5 & $42 \cdot 3$ & $4 \cdot 2$ \\
\hline
\end{tabular}

${ }^{*}$ For details of procedures, see p. 142.

† Comprised intermediate-density lipoproteins, LDL and HDL. 

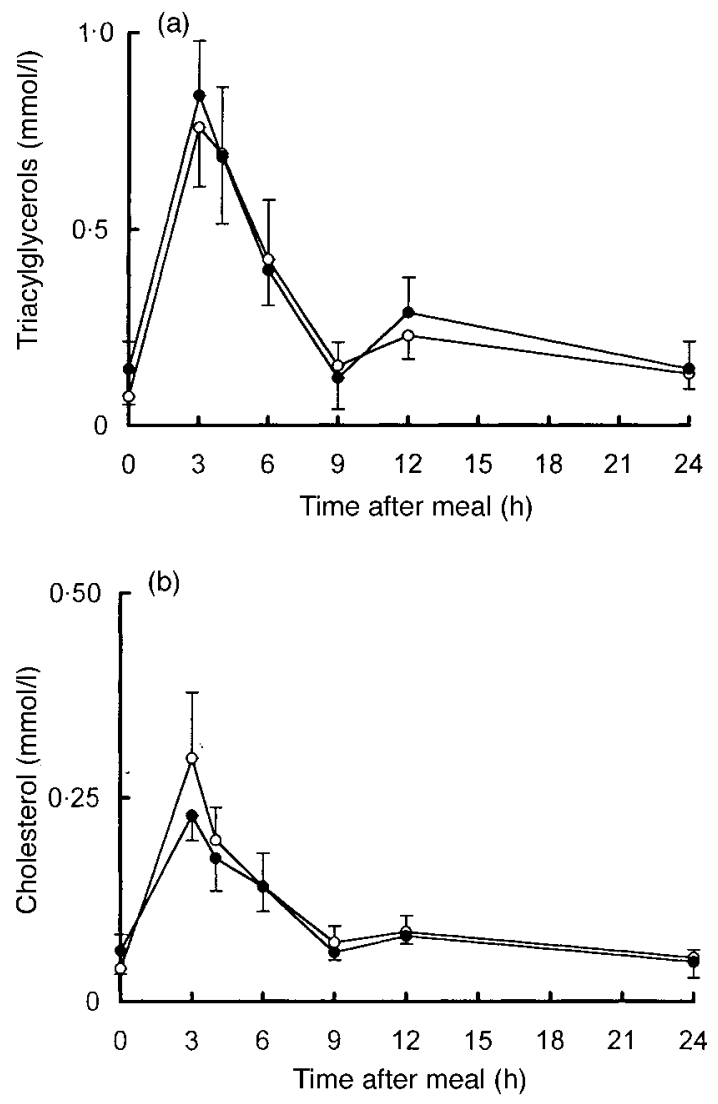

Fig. 1. Postprandial chylomicron concentrations of (a) triacylglycerols and (b) cholesterol in healthy men after consumption of a test meal with $(O)$ and without $(\bullet)$ stanyl ester supplementation. Values are means with their standard errors represented by vertical bars for ten men. For details of procedures, see p. 142.

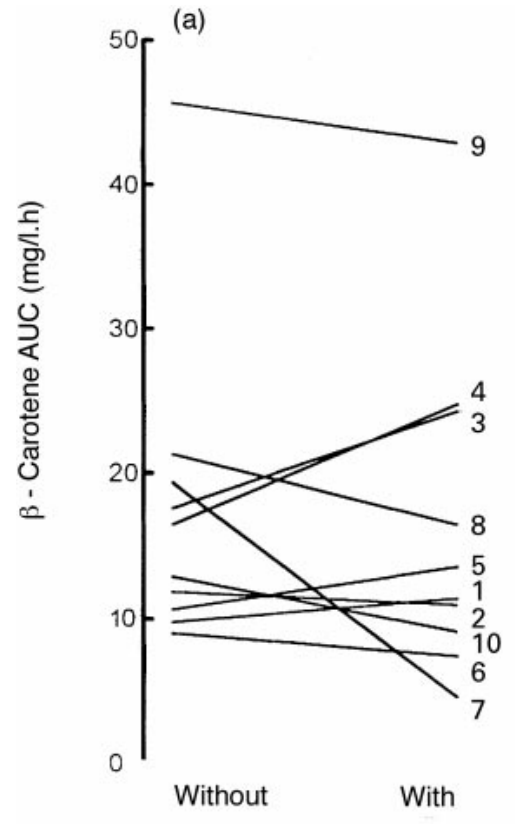

Stanyl ester supplementation
Table 4. Peak serum concentration times (h) of $\alpha$-tocopherol, $\beta$ carotene, retinyl palmitate, squalene, triacylglycerols and cholestero after consumption of a test meal with and without stanyl ester supplementation in healthy male volunteers $\ddagger$

(Mean values with their standard errors for ten men)

\begin{tabular}{lccccc}
\hline & \multicolumn{2}{c}{ With stanyl ester§ } & & \multicolumn{2}{c}{ Without stanyl ester } \\
\cline { 2 - 3 } \cline { 5 - 6 } & Mean & SE & & Mean & SE \\
\hline$\alpha$-Tocopherol & 15.6 & 2.4 & & 13.8 & 2.5 \\
-Carotene $^{*}$ & 22.0 & 2.0 & & 22.8 & 1.0 \\
Retinyl palmitate $\dagger$ & 4.8 & 0.4 & & 6.4 & 1.0 \\
Squalene $\dagger$ & 6.7 & 0.8 & & 7.2 & 0.9 \\
Triacylglycerols & 3.5 & 0.3 & & 4.1 & 0.9 \\
Cholesterol & 5.8 & 2.1 & & 4.5 & 0.9 \\
\hline
\end{tabular}

Mean values were significantly different from the other peak times: ${ }^{*} P<0.05$ Mean values were significantly different from those for triacylglycerols: $\uparrow P<$ 0.05

‡ For details of procedures, see p. 142.

$\S$ Stanyl ester supplementation had no significant effect on peak serum concentration times.

Serum cholesterol precursor: cholesterol were similar and practically unchanged from the baseline in both fatload tests (data not shown). However, for postprandial serum campesterol:cholesterol there was a significant time $\times$ stanyl ester interaction for $0-12 \mathrm{~h} \quad(P=0 \cdot 01$, ANOVA for repeated measures). In the follow-up comparisons by one-way ANOVA, campesterol: cholesterol was significantly lower at $6(P=0.046)$ and $9(P=0.009) \mathrm{h}$ after the addition of stanyl esters to the test meals (Fig. 3). The decrease in the ratio was due to a net decrease in serum campesterol concentration after the stanyl ester-supplemented meal. Serum sitosterol : cholesterol values were not consistently changed by stanyl esters (data not shown). 


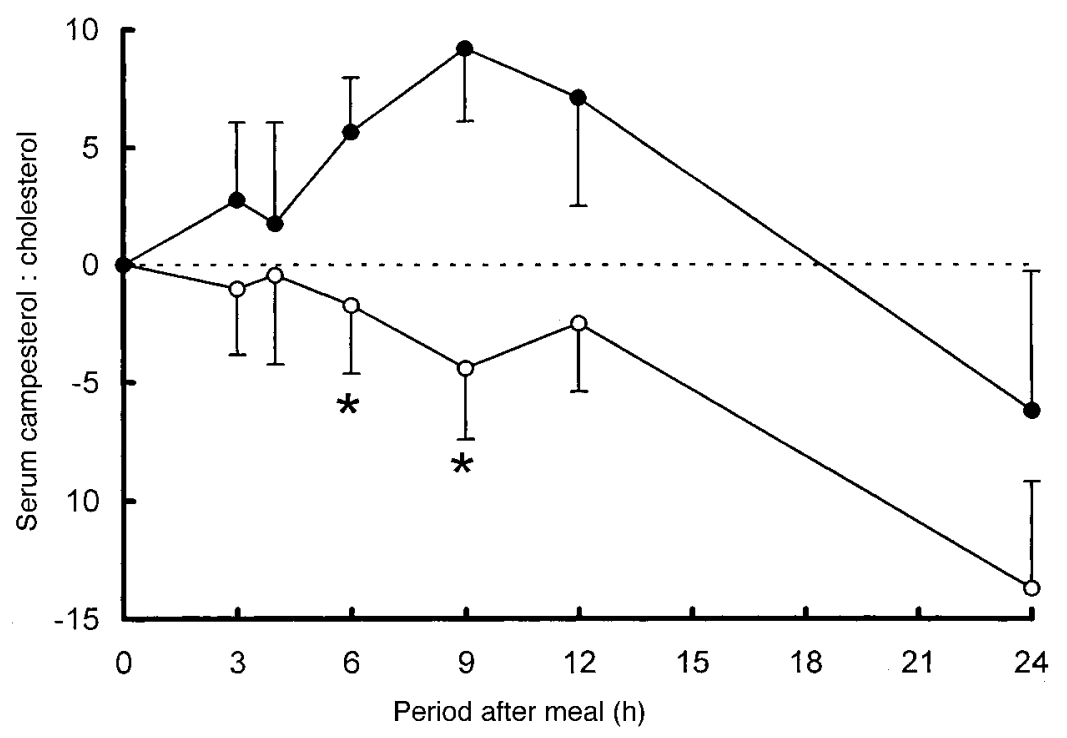

Fig. 3. Postprandial change in serum campesterol: cholesterol in healthy men after consumption of a test meal with $(O)$ and without $(\bullet)$ stanyl ester supplementation. Values are means with their standard errors represented by vertical bars for ten men. Mean values were significantly different from those without stanyl ester supplementation: ${ }^{*} P<0.05$. For details of procedures, see p. 142.

\section{Discussion}

Stanyl esters, which are supposed to compete with cholesterol in micelles (Hassan \& Rampone, 1980; Ikeda et al. 1989), could theoretically interfere also with the absorption of fat-soluble vitamins. However, long-term (12 months) treatment with stanyl ester-containing margarine did not lower serum retinol and vitamin $\mathrm{D}$ concentrations or $\alpha$-tocopherol : cholesterol; only the serum $\beta$-carotene ratios were reduced (Gylling et al. 1999a). However, treatment for 8-20 weeks did not lower $\beta$-carotene levels or ratios (Hallikainen \& Uusitupa, 1999; Hallikainen et al. 2000). The present study showed for the first time that a single dose of $1 \mathrm{~g}$ dietary stanyl, consumed as its esters in margarine, did not detectably interfere with the serum or lipoprotein responses of simultaneously-ingested cholesterol, triacylglycerol, $\alpha$-tocopherol, $\beta$-carotene, retinol and retinyl palmitate for $24 \mathrm{~h}$, whereas it lowered campesterol: cholesterol after 6-9 h reflecting reduced sterol absorption efficiency.

Intestinal absorption of $\alpha$-tocopherol, $\beta$-carotene and retinol is variable, ranging from 9 to $75 \%$ (Goodman et al. 1966; Meydani, 1995; Biesalski, 1997). In addition, the individual variation in plasma levels following the same oral dose is large (Borel et al. 1998). Accordingly, we decided to use variable vitamin and $\beta$-carotene doses in order to observe any effects of dosage on changes in absorption. The smallest doses were similar to physiological daily intakes. Since different doses of vitamins and $\beta$ carotene were used, the post-absorptive responses could not be compared in aggregate. However, there were no consistent effects of stanyl esters on AUC for $\alpha$-tocopherol, $\beta$-carotene or retinyl palmitate, and no relation to the dosage was observed.

Post-absorptive $\alpha$-tocopherol concentrations have previously been observed to decline in chylomicrons after $12 \mathrm{~h}$, but concentrations in LDL and HDL remain elevated for much longer, up to $24-48 \mathrm{~h}$ after oral administration (Traber et al. 1998). Similarly, in the present study, peak $\alpha$-tocopherol concentrations occurred later than those of retinyl palmitate and triacylglycerols, and were not affected by stanyl esters.

$\beta$-carotene is absorbed by different pathways compared with retinol (Cornwell et al. 1962; Goodman et al. 1966; Goodman \& Olson, 1969; Hollander \& Ruble, 1978), involving the portal vein system in addition to the lymphatic system (Johnson \& Russell, 1992). Serum concentrations rose steadily towards the end of the $24 \mathrm{~h}$ study period, which is in concordance with findings of earlier studies (Cornwell et al. 1962; Johnson et al. 1997). It has been assumed that $\beta$-carotene is released from the mucosal cells more slowly than its retinoid metabolites (Hollander \& Ruble, 1978), probably due to its lower polarity when compared with the fat-soluble vitamins. The large inter-individual variation in $\beta$-carotene responses in the present study can partly explain the lack of doseresponse, since the intra-individual responses of ingested $\beta$ carotene have been shown to be small (O'Neill \& Thurnham, 1998).

Serum retinol concentrations were unchanged after retinol ingestion, a finding observed previously (Rasmussen et al. 1991). Retinyl palmitate concentrations rose markedly and similarly in chylomicrons after both test meals, which together with the unaltered triacylglycerol and cholesterol concentrations and AUC suggest that chylomicron formation is not altered by stanyl esters. In addition, postprandial squalene curves, which have previously been shown to reflect postprandial chylomicron remnants (Gylling \& Miettinen, 1994), were almost identical to those of retinyl palmitate and were not affected by stanyl esters. 
Postprandial cholesterol was not altered by a single dose of stanyl esters. It is apparent that both lowered serum cholesterol (Miettinen et al. 1995) and $\beta$-carotene concentrations in long-term feeding (Gylling et al. 1999a) are a result of chronic stanyl ester consumption. The mechanism is related to a diminished intestinal pool of cholesterol and a compensatory alteration in whole-body cholesterol metabolism. Our earlier observation of reduced postprandial VLDL-squalene and VLDL-retinyl palmitate concentrations after 1-2 weeks of stanyl ester consumption is obviously related to long-term stanyl ester feeding, which is associated with enhanced postprandial lipoprotein clearance (Relas et al. 2000). Thus, the cholesterollowering effect of stanyl esters also seems to be based on mechanisms that take place during regular long-term consumption (Miettinen et al. 1995) as well as the potential ability of stanyl esters to interfere with the absorption of biliary cholesterol. On the other hand, squalene, a cholesterol precursor administered with the fat load, might have contributed to intestinal cholesterol synthesis and thus increased cholesterol concentrations in chylomicrons and VLDL, thereby counteracting the effect of stanyl esters on post-absorptive cholesterol values.

Serum plant sterol : cholesterol decreases and cholesterol precursor:sterol increases during long-term stanyl ester feeding (Gylling et al. 1999b), suggesting that cholesterol absorption efficiency is decreased followed by a compensatory increase in cholesterol synthesis. The present study showed that ingestion of $1 \mathrm{~g}$ stanyl esters acutely reduced serum campesterol concentration and campesterol : cholesterol up to $12 \mathrm{~h}$ after ingestion. Sterols, including plant sterols campesterol and sitosterol, are in equilibrium with the exchangeable sterol pools in lipoproteins and in tissues, and are ultimately eliminated from the body via bile. Thus, it can be assumed that the drop in concentration of campesterol is caused by inhibited absorption from the intestinal pool of campesterol. Accordingly, the reduced postprandial campesterol ratio after $3-12 \mathrm{~h}$ reflected reduced sterol (including cholesterol) absorption efficiency, even though no changes were observed in postprandial cholesterol concentrations. It is possible that no consistent changes in sitosterol were observed as sitosterol is less well absorbed (4-5\%) than campesterol (10\%; Heinemann et al. 1993).

In conclusion, stanyl esters which are known to inhibit cholesterol absorption and reduce serum total and LDLcholesterol levels do not detectably interfere with the absorption of simultaneously-ingested $\alpha$-tocopherol, $\beta$ carotene or retinol during a $24 \mathrm{~h}$ follow-up. The mechanism of lowered $\beta$-carotene concentrations related to chronic feeding remains to be further investigated.

\section{Acknowledgements}

The present study was supported by grants from the Clinical Research Institute of the Helsinki University Central Hospital, the Finnish Academy, Council of Medical Sciences and Helsinki University Central Hospital. The excellent technical assistance of Ms Leena Kaipiainen, Pia Hoffström, Anja Salolainen, Orvokki Ahlroos and Ritva
Nissilä is greatly acknowledged. The margarine was kindly supplied by Raisio Group, Raisio, Finland.

\section{References}

Becker M, Staab D \& von Bergmann K (1993) Treatment of severe familial hypercholesterolemia in childhood with sitosterol and sitostanol. Journal of Pediatrics 122, 292-296.

Biesalski HK (1997) Bioavailability of vitamin A. European Journal of Clinical Nutrition 51, Suppl. 1, S71-S75.

Borel P, Grolier P, Mekki N, Boirie Y, Rochette Y, Le Roy B, Alexandre-Gouabau MC, Lairon D \& Azais-Braesco V (1998) Low and high responders to pharmacological doses of $\beta$ carotene: proportion in the population, mechanisms involved and consequences on $\beta$-carotene metabolism. Journal of Lipid Research 39, 2250-2260.

Cornwell DG, Kruger FA \& Robinson HB (1962) Studies on the absorption of beta-carotene and the distribution of total carotenoid in human serum lipoproteins after oral administration. Journal of Lipid Research 3, 65-70.

Gallo-Torres HE (1970) Obligatory role of bile for the intestinal absorption of vitamin E. Lipids 5, 379-384.

Goodman DS, Blomstrand R, Werner B, Huang HS \& Shiratori T (1966) The intestinal absorption and metabolism of vitamin A and $\beta$-carotene in man. Journal of Clinical Investigation 45, $1615-1623$.

Goodman DS, Huang HS \& Shiratori T (1965) Tissue distribution and metabolism of newly absorbed vitamin A in the rat. Journal of Lipid Research 6, 390-396.

Goodman DS \& Olson JA (1969) The conversion of all-trans $\beta$ carotene into retinal. In Methods in Enzymology, vol. 15, pp. 462-475 [RB Clayton, editors]. New York: Academic Press Inc.

Gylling H \& Miettinen TA (1994) Postabsorptive metabolism of dietary squalene. Atherosclerosis 106, 169-178.

Gylling H, Puska P, Vartiainen E \& Miettinen TA (1999a) Retinol, vitamin D, carotenes and $\alpha$-tocopherol in serum of a moderately hypercholesterolemic population consuming sitostanol ester margarine. Atherosclerosis 145, 279-285.

Gylling H, Puska P, Vartiainen E \& Miettinen TA (1999b) Serum sterols during stanol ester feeding in a mildly hypercholesterolemic population. Journal of Lipid Research 40, 593-600.

Hallikainen MA, Sarkkinen ES \& Uusitupa MIJ (2000) Plant stanol esters affect serum cholesterol concentrations of hypercholesterolemic men and women in a dose-dependent manner. Journal of Nutrition 130, 767-776.

Hallikainen MA \& Uusitupa MIJ (1999) Effects of two low-fat stanol ester-containing margarines on serum cholesterol concentrations as part of a low-fat diet in hypercholesterolemic subjects. American Journal of Clinical Nutrition 69, 403-410.

Hassan AS \& Rampone AJ (1980) Effect of $\beta$-sitostanol (5- $\alpha$ stigmastan-3 $\beta$-ol) on cholesterol absorption from micellar solutions in jejunal loops in situ. Steroids 36, 731-741.

Heinemann T, Axtmann G \& von Bergmann K (1993) Comparison of intestinal absorption of cholesterol with different plant sterols in man. European Journal of Clinical Investigation 23, 827-831.

Heinemann T, Kullak-Ublick GA, Pietruck B \& von Bergmann K (1991) Mechanisms and action of plant sterols on inhibition of cholesterol absorption. Comparison of sitosterol and sitostanol. European Journal of Clinical Pharmacology 40, Suppl. 1, S59S63.

Heinemann T, Leiss O \& von Bergmann K (1986) Effect of lowdose sitostanol on serum cholesterol in patients with hypercholesterolemia. Atherosclerosis 61, 219-223. 
Hollander D (1981) Intestinal absorption of vitamins A, E, D and K. Journal of Laboratory and Clinical Medicine 97, 449-462.

Hollander D, Rim E \& Muralidhara KS (1975) Mechanism and site of small intestinal absorption of $\alpha$-tocopherol in the rat. Gastroenterology 68, 1492-1499.

Hollander D \& Ruble PE Jr (1978) $\beta$-carotene intestinal absorption: bile, fatty acid, $\mathrm{pH}$, and flow rate effects on transport. American Journal of Physiology 235, E686-E691.

Ikeda I \& Sugano M (1978) Comparison of absorption and metabolism of $\beta$-sitosterol and $\beta$-sitostanol in rats. Atherosclerosis 30, 227-237.

Ikeda I, Tanabe Y \& Sugano M (1989) Effects of sitosterol and sitostanol on micellar solubility of cholesterol. Journal of Nutritional Science and Vitaminology 35, 361-369.

Johnson EJ, Qin J, Krinsky NI \& Russell RM (1997) Ingestion by men of a combined dose of $\beta$-carotene and lycopene does not affect the absorption of $\beta$-carotene but improves that of lycopene. Journal of Nutrition 127, 1833-1837.

Johnson EJ \& Russell RM (1992) Distribution of orally administered $\beta$-carotene among lipoproteins in healthy men. American Journal of Clinical Nutrition 56, 128-135.

Kanai M, Raz A \& Goodman DS (1968) Retinol-binding protein: the transport protein for vitamin A in human plasma. Journal of Clinical Investigation 47, 2025-2044.

Mattson FH, Grundy SM \& Crouse JR (1982) Optimizing the effect of plant sterols on cholesterol absorption in man. American Journal of Clinical Nutrition 35, 697-700.

Meydani M (1995) Vitamin E. Lancet 345, 170-175.

Miettinen TA (1988) Cholesterol metabolism during ketoconazole treatment in man. Journal of Lipid Research 29, 43-51.

Miettinen TA \& Koivisto P (1983) Non-cholesterol sterols and bile acid production in hypercholesterolaemic patients with ileal bypass. In Bile Acids and Cholesterol in Health and Disease, pp. 183-187 [G Paumgartner, A Stiehl and W Gerok, editors]. Lancaster: MTP Press Ltd.

Miettinen TA, Puska P, Gylling H, Vanhanen H \& Vartiainen E (1995) Reduction of serum cholesterol with sitostanol-ester margarine in a mildly hypercholesterolemic population. New England Journal of Medicine 333, 1308-1312.
O'Neill ME \& Thurnham DI (1998) Intestinal absorption of $\beta$ carotene, lycopene and lutein in men and women following a standard meal: response curves in the triacylglycerol-rich lipoprotein fraction. British Journal of Nutrition 79, 149-159.

Pollak OJ (1953) Reduction of blood cholesterol in man. Circulation 7, 702-706.

Rasmussen HM, Dallal GE, Phelan E \& Russel RM (1991) Serum concentrations of retinol and retinyl esters in adults in response to mixed vitamin A and carotenoid containing meals. Journal of the American College of Nutrition 10, 460-465.

Relas H, Gylling H \& Miettinen TA (2000) Effect of stanol ester on postabsorptive squalene and retinyl palmitate. Metabolism 49, 473-478.

Schäfer Elinder L \& Walldius G (1992) Simultaneous measurement of serum probucol and lipid-soluble antioxidants. Journal of Lipid Research 33, 131-137.

Sugano M, Morioka H \& Ikeda I (1977) A comparison of hypocholesterolemic activity of $\beta$-sitosterol and $\beta$-sitostanol in rats. Journal of Nutrition 107, 2011-2019.

Tilvis RS \& Miettinen TA (1986) Serum plant sterols and their relation to cholesterol absorption. American Journal of Clinical Nutrition 43, 92-97.

Traber MG, Burton GW, Ingold KU \& Kayden HJ (1990) RRRand SRR- $\alpha$-tocopherols are secreted without discrimination in human chylomicrons, but, RRR- $\alpha$-tocopherol is preferentially secreted in very low density lipoproteins. Journal of Lipid Research 31, 675-685.

Traber MG, Ingold KU, Burton GW \& Kayden HJ (1988) Absorption and transport of deuterium-substituted $2 \mathrm{R}, 4^{\prime} \mathrm{R}, 8^{\prime} \mathrm{R}$ $\alpha$-tocopherol in human lipoproteins. Lipids 23, 791-797.

Traber MG, Rader D, Acuff RV, Ramakrishnan R, Brewer HB \& Kayden H (1998) Vitamin E dose-response studies in humans with use of deuterated RRR- $\alpha$-tocopherol. American Journal of Clinical Nutrition 68, 847-853.

Warnick GR \& Alberts JJ (1982) Quantitation of lipoproteins. In Manual of Laboratory Operations, Lipid Research Clinics Program, Lipid and Lipoprotein Analysis, pp. 63-77 [A Hainline, J Karon and $\mathrm{K}$ Lippel, editors]. Bethesda, MD: National Institutes of Health. 